\title{
Placenta accreta not previa: a rare case report of placenta accreta in an unscarred uterus
}

\author{
Renuka Malik*, Swati Singh, Jaya Chawla, Meenakshi Bhardwaj
}

Department of Obstetrics and Gynecology, ABVIMS and RML Hospital, New Delhi, India

Received: 12 September 2019

Accepted: 07 November 2019

\section{*Correspondence:}

Dr. Renuka Malik,

E-mail: renucam@yahoo.co.in

Copyright: () the author(s), publisher and licensee Medip Academy. This is an open-access article distributed under the terms of the Creative Commons Attribution Non-Commercial License, which permits unrestricted non-commercial use, distribution, and reproduction in any medium, provided the original work is properly cited.

\begin{abstract}
Placenta accreta spectrum disorders are usually associated with direct surgical scar such as caesarean delivery, surgical termination of pregnancy, Dilatation and curettage, Myomectomy, Endometrial resection and Asherman's syndrome. It can also be associated with non-surgical scar and uterine anomalies. Rarely it can be encountered in unscarred uterus. Mrs X, 35-year female, unbooked patient, G7P2L2A4 with nine months of amenorrhoea reported in emergency of RML Hospital on 30/07/2019 with history of labour pains since 2 days. Patient gave history of four dilatation and curettage for incomplete abortion. On examination patient was found to be severely anaemic (Hb -6 gm). 2 Packed RBC were transfused preoperatively. There was no progress in labour beyond $6 \mathrm{~cm}$ for 4 hours. Patient was thus taken for LSCS for NPOL, with blood on flow. Intraoperatively, after delivery of the baby placenta which was fundo-posterior did not separate. In view of parity and morbidly adherent placenta (clinical grade III), subtotal hysterectomy was done. Patient was transfused 4 PRBC, 4 FFP and 2 platelets. Uterus with placenta in situ was sent for histopathology. Patient was in ICU for 2 days and recovered well. Post-operative period was uneventful. Placenta accreta is defined as abnormal trophoblast invasion of whole or a part of placenta into myometrium of uterine wall. Caesarean delivery is associated with increased risk of placenta accrete and the risk increases with each caesarean section, from $0.3 \%$ in woman with one previous caesarean delivery to $6.47 \%$ for woman with five or more caesarean deliveries. Placenta accreta spectrum disorders occur in $3 \%$ of woman diagnosed with placenta previa and no prior caesarean. In the developing world, the obstetrician should be prepared to encounter un diagnosed placenta accrete even in absence of previous LSCS. Curretage following MTP is also a risk factor, so vigourous currettage should be avoided to prevent endometrial damage.
\end{abstract}

Keywords: Caesarean hysterectomy, Placental spectrum disorders, Placenta accreta

\section{INTRODUCTION}

In the present clinical situation, it is common to find caesarean section as a predisposing risk factor in over $90 \%$ of cases of placenta accreta. Placenta accreta is labelled as a $20^{\text {th }}$ century iatrogenic uterine disease. ${ }^{1}$

However, the obstetrician should be prepared to encounter a total placenta accreta in an unscarred uterus as happened in our case.

\section{CASE REPORT}

Mrs X, 35-year female, unbooked patient, G7P2L2A4 reported in emergency of RML Hospital on 30/07/2019 with full term pregnancy with labour pains since 2 days with severe anaemia. She had come LAMA from a private nursing home when they had decided for caesarean and had asked for blood transfusion. She had a haemoglobin report of $5.8 \mathrm{gm} / \mathrm{dl}$. Her ultrasound report was normal. Clinically patient was very pale; pulse was 
$110 /$ min with normal BP. She was getting good contractions and was $6 \mathrm{~cm}$ dilated. 4 packed RBC were arranged for transfusion and She was left for vaginal delivery. 4 hours later, after transfusion of 2 packed cells patient had not progressed beyond $6 \mathrm{~cm}$ decision for LSCS under spinal anaesthesia was taken by resident doctor and consultant informed. Intraoperatively, after delivery of the baby the placenta which was fundo posterior did not separate for $45 \mathrm{~min}$, after giving oxytocin 5 IU. Gently, on exploration the placenta was found to be totally adherent to posterior wall (Figure 1-3).

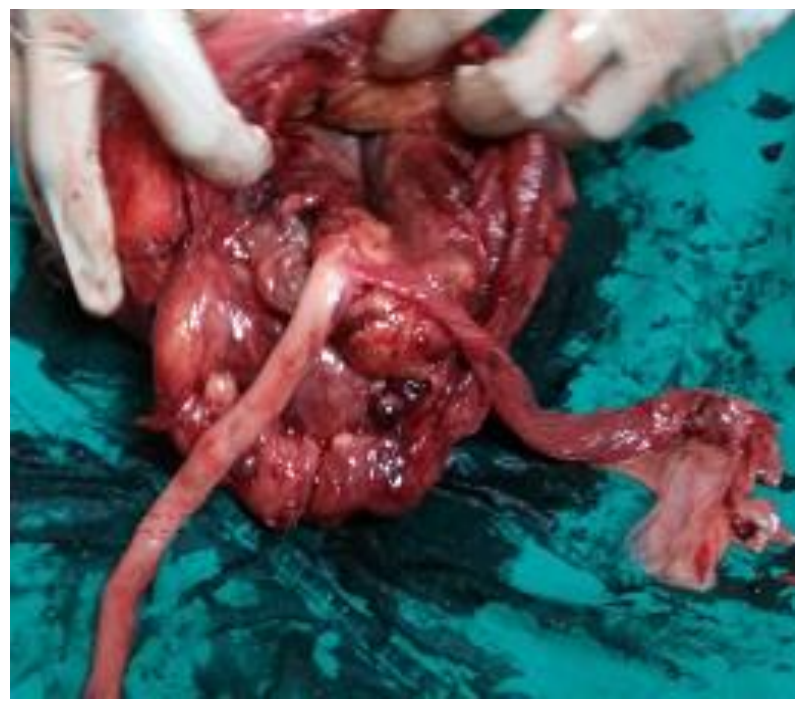

Figure 1: Hystrectomy specimen showing adherent placenta.

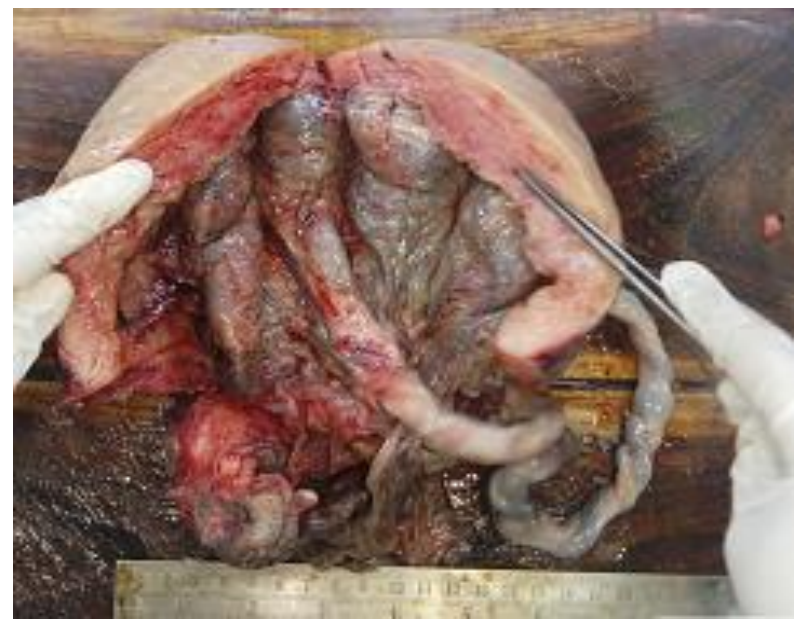

Figure 2: Fundo-posterior attachment of placental specimen.

No attempt was made to forcibly remove the placenta. Patient had been started on nor adrenalin drip by the anaesthetist by this time and patient shifted to general anaesthesia and 3 PRBC and 3 FFP had been transfused till now. In view of parity and morbidly adherent placenta subtotal hysterectomy was decided and proceeded with. Uterus with placenta in situ was sent for Histopathology.
Patient had a total of 4 PRBC, 4 FFP and 2 platelet transfusions. She was shifted to ICU for 2 days and had an uneventful recovery. In her post-operative stay she gave history of 4 MTP with history of curettage 4 times. Patient was discharged on $10^{\text {th }}$ post-operative day after stitch removal. Histopathology of specimen was reported as total placenta accreta (Figure 4).

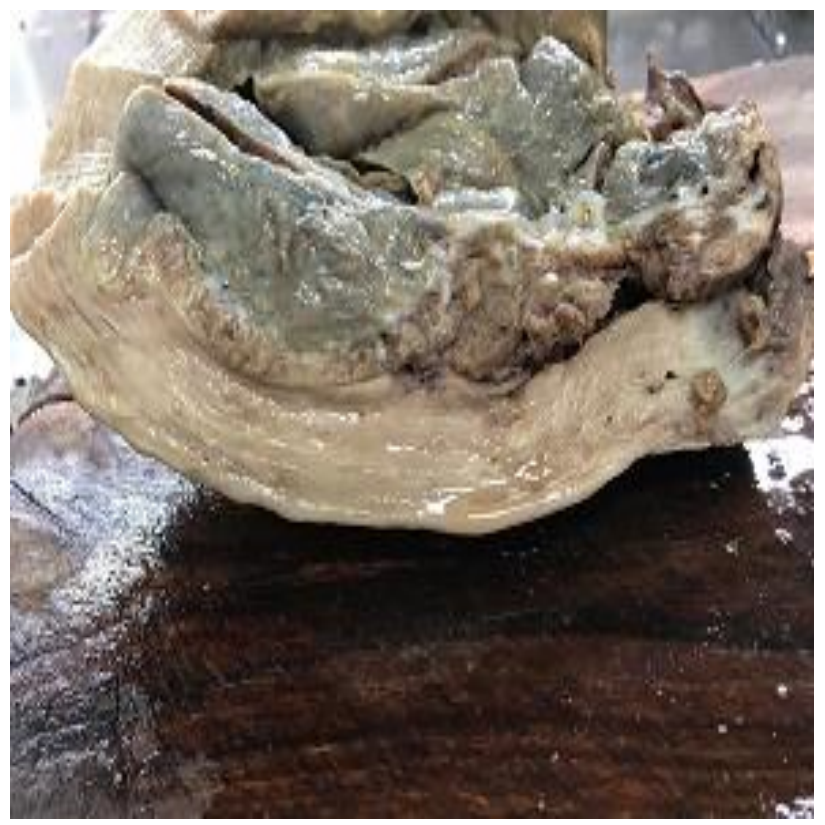

Figure 3: Mounted specimen of placenta accreta.

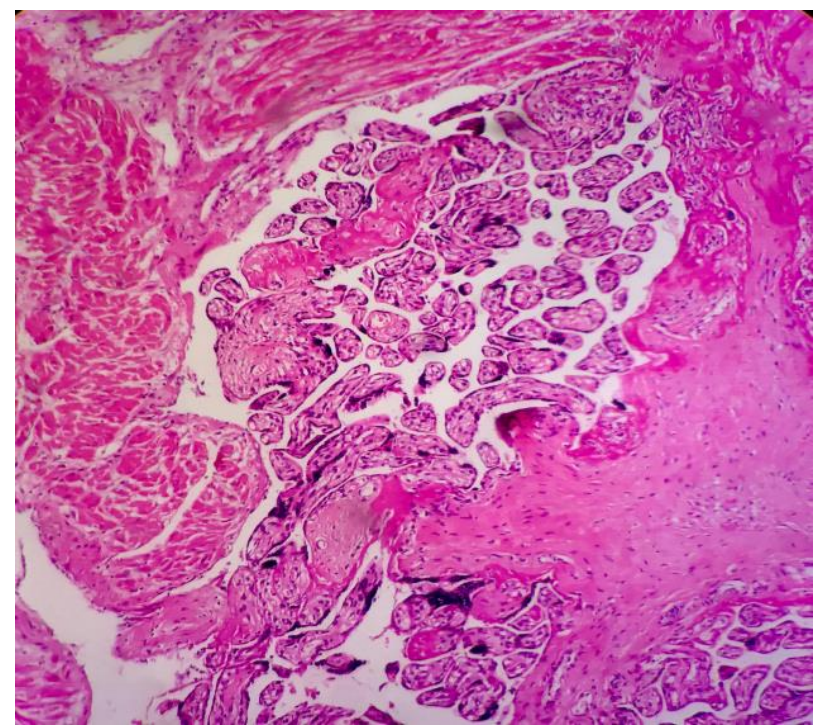

Figure 4: Histopathological examination showing placenta accreta.

\section{DISCUSSION}

Women with either an anterior or posterior placenta previa are at increased risk for placenta accreta and this risk increases markedly when the placenta overlies a uterine scar. Additional reported risk factors for placenta accreta include maternal age and multiparty, other prior 
uterine surgery, prior uterine curettage, uterine irradiation, endometrial ablation, asherman syndrome, uterine leiomyomata, uterine anomalies, hypertensive disorders of pregnancy and smoking. ${ }^{2}$ In this modern Era of caesarean sections, it is rare to find placenta accreta in unscarred uterus which was the case in past century. However, the obstetrician should be prepared to rarely encounter placenta accreta in unscarred uterus as happened in our case.

Placenta accreta occurs when all or part of the placenta attaches abnormally to the myometrium. Three grades of abnormal placental attachment are defined according to the depth of invasion. It is termed as placenta accreta when chorionic villi attach to the myometrium, rather than being restricted within the decidua basalis, Increta when chorionic villi invade into the myometrium and Percreta when chorionic villi invade through the myometrium. ${ }^{2,3}$

Hysterectomy remains the definitive surgical treatment for placenta accreta spectrum (PAS) disorders, especially for its invasive forms, and a primary elective caesarean hysterectomy is the safest and most practical option for most low- and middle-income countries where diagnostic, follow up, and additional treatments are not available. In cases encountered where the placenta accreta is not associated with caesarean scar and is not covering cervix a subtotal hysterectomy can be lifesaving.

A total $60 \%$ of obstetricians attempt placental removal with PAS disorders, which is to be avoided. In the setting of planned immediate hysterectomy for PAS disorders, no attempt at manual separation should be undertaken because leaving the placenta in situ is associated with lower blood loss. Therefore, utero-tonic agents are not administered at caesarean hysterectomy for PAS disorders, unless placental removal is imminent ruling out PAS disorders. ${ }^{4,5}$ In our case though the placenta accreta was not pre diagnosed no forcible attempts were made to remove placenta thus minimising blood loss in an already compromised patient. The main risk associated with any form of PAS disorder is massive obstetric haemorrhage, which leads to secondary complications including coagulopathy, multisystem organ failure, and death. Surgical risks increase with the depth of placental invasion.

Total hysterectomy is the recommended surgical method for emergent peripartum hysterectomy owing to the potential risk of malignancy developing in the cervical stump, the need for regular cervical cytology, and other associated problems such as bleeding or discharge. The survey of specialists regarding their management of PAS disorders was split with regard to the total versus subtotal hysterectomy. Just over half $(55 \%)$ of all providers performed total procedures, with $45 \%$ reporting use of supracervical hysterectomy. Proponents of subtotal hysterectomy reported decreased blood loss, blood transfusions, perioperative complications and shorter operating time. However, subtotal hysterectomy may not be effective in the management of placenta increta or percreta, if cervical involvement is present and a total hysterectomy should be the preferred option in these case. $^{6-9}$ In addition, subtotal hysterectomy has not been shown to provide protection against urinary tract injury compared with total hysterectomy in surgeries for PAS disorders. ${ }^{10}$ In our case as the patient was already anaemic and on nor adrenalin drip, a subtotal hysterectomy was a quick procedure and did not require more blood transfusion. However, in other circumstances a total hysterectomy would be the procedure of choice.

In this case, what appeared to be an unscarred uterus was in fact a scarred uterus following curretage for MTP, done 4 times, a history which was elicited in post operative period. Along with reducing Cesarean rate, the incidence of surgical abortion should also be reduced by resorting to early medical abortion. The practice of rigorous check curettage scars the uterus.

\section{CONCLUSION}

In the developing world, the obstetrician should be prepared to encounter un-diagnosed placenta accreta even in absence of previous LSCS. Women with PAS disorders need a multi-disciplinary approach with availability blood, ICU and specialised anaesthetists.

\section{Funding: No funding sources \\ Conflict of interest: None declared \\ Ethical approval: Not required}

\section{REFERENCES}

1. Jauniaux E, Jurkovic D. Placenta accreta: Pathogenesis of a $20^{\text {th }}$ century iatrogenic uterine disease. Placenta. 2012;33:244-51.

2. Belfort M. Placenta accreta. Ame J Obstet Gynaecol. 2010;203(5):430-9.

3. Solheim KN, Esakoff TF, Little SE, Cheng YW, Sparks TN, Caughey AB. The effect of cesarean delivery rates on the future incidence of placenta previa, placenta accreta, and maternal mortality. J Matern Fetal Neonatal Med. 2011;24:1341-6.

4. Jauniaux E, Chantraine F, Silver RM, Langhoff-Roos J. For the FIGO placenta accreta diagnosis and management expert consensus panel. FIGO consensus guidelines on placenta accreta spectrum dis-orders: Epidemiol. Int $\mathbf{J}$ Gynecol Obstet. 2018;140:265-73.

5. Jauniaux E, Grobmann W. Caesarean section: Introduction to the "World's No 1. Surgical Procedure ", Textbook of Caesarean Section. Oxford: Oxford University Press; 2016:1-8.

6. Allen L, Jauniaux E, Hobson S, Paillon-Smith J, Belfort MA. for the FIGO Placenta Accreta Diagnosis and Management Expert Consensus Panel. FIGO consensus guidelines on placenta accreta 
spectrum dis-orders: Nonconservative surgical management. Int J Gynecol Obstet. 2018;140:28190.

7. Esakoff TF, Handler SJ, Granados JM, Caughey AB. PAMUS: Placenta accreta management across the United States. J Matern Fetal Neonatal Med. 2012;25:761-5.

8. Matsubara S, Kuwata T, Usui R. Important surgical measures and techniques at cesarean hysterectomy for placenta previa accreta. Acta Obstet Gynecol Scand. 2013;92:372-7.

9. Weiniger CF, Kabiri D, Ginosar Y, Ezra Y, Shachar B, Lyell DJ. Suspected placenta accreta and cesarean hysterectomy: Observational cohort utilizing an intraoperative decision strategy. Eur $\mathrm{J}$ Obstet Gynecol Reprod Biol. 2016;198:56-61.

10. Tam KB, Dozier J, Martin JN. Approaches to reduce urinary tract injury during management of placenta accreta, increta, and percreta: a systematic review. J Matern Fetal Neonatal Med. 2012;25:329-34.

Cite this article as: Malik R, Singh S, Chawla J, Bhardwaj M. Placenta accreta not previa: a rare case report of placenta accreta in an unscarred uterus. Int J Reprod Contracept Obstet Gynecol 2019;8:5050-3. 